\title{
Influence of Maternal Oral Health Knowledge and Practices on the Child's Oral Health
}

\author{
Renuka P Chinchalkar ${ }^{1}$, Nikhil Marwah², Thejavinuo ${ }^{3}$, Shavan Kumar Yadav ${ }^{4}$
}

\begin{abstract}
Introduction: Children younger than 7 years of age spend most of their time with parents and guardians, especially mothers. Maternal oral health knowledge, belief, and attitudes influence the oral health maintenance, dietary habits, and healthy behavior of their children. The aim of this study was to assess the impact of mother's oral healthcare knowledge on the oral health status of their child.

Materials and methods: A total of 100 mothers and children visiting the department of pedodontics and preventive dentistry were randomly selected. A questionnaire, including parent's name, age, literacy levels, socioeconomic status, dietary practices, and oral hygiene practices, was designed to assess the knowledge of the mothers regarding oral health of themselves and their child. Later the child's oral health status was examined.

Results and conclusion: The results were statistically analyzed, and it was concluded that there is a significant influence of mother's oral health knowledge and practices on the child's oral health.

Keywords: Children, Habits, Mother, Oral health.

Journal of Mahatma Gandhi University of Medical Sciences \& Technology (2019): 10.5005/.jp-journals-10057-0109
\end{abstract}

\section{INTRODUCTION}

A major role has been played by parents in imparting information and encouragement to their children for healthy lives. ${ }^{1}$ Their attitudes have notable influence on the children's oral health and overall health. ${ }^{2}$ Most of the behavioral habits are adopted by children at home, especially mothers being the chief mentor for behavior. ${ }^{3}$ Children younger than 7 years mostly spend their time with parents and guardians, especially mothers. Children's oral health maintenance and outcomes are greatly influenced by their parents. Children imitate their parents who are available and who provide valued role models for oral healthcare practices. ${ }^{4}$

The positive attitude of parents toward oral health and dentists leads to better oral health of their children. Implementation of effective disease preventive strategies needs basic knowledge of caries causing factors, importance of deciduous teeth, and oral hygiene maintenance. ${ }^{5}$ If these habits are taught in early childhood, they are inculcated into the child's daily practice and need only positive reinforcements later. ${ }^{4}$ Despite the change in roles and responsibilities within the family, the mother stills plays an important role in child's oral health habits and condition. ${ }^{6}$ Teaching the mother about the child's oral hygiene, the practices, and basic knowledge will reduce the prevalence of dental and oral diseases substantially. ${ }^{7}$

\section{Materials and Methods}

This present study was carried out in a department of pedodontics and preventive dentistry, Jaipur city of Rajasthan. The aim was to assess the influence of mother's oral healthcare knowledge on the oral health status of their child. Children in the age-group of 3-7 years were randomly selected from the study. A total of 100 mothers were required to fill the questionnaire and 100 children to be screened for OHI's index.

A questionnaire was prepared to assess the oral hygiene knowledge and practice of mothers. Questionnaire consisted of 10 closed-ended questions. First part was demographic information,
${ }^{1-4}$ Department of Pedodontics and Preventive Dentistry, Mahatma Gandhi Dental College and Hospital, Jaipur, Rajasthan, India

Corresponding Author: Renuka P Chinchalkar, Department of Pedodontics and Preventive Dentistry, Mahatma Gandhi Dental College and Hospital, Jaipur, Rajasthan, India, Phone: +91 8600778359 , e-mail: r1234chinchalkar@gmail.com

How to cite this article: Chinchalkar RP, Marwah N, Thejavinuo, et al. Influence of Maternal Oral Health Knowledge and Practices on the Child's Oral Health. J Mahatma Gandhi Univ Med Sci Tech 2019;4(3):64-67.

Source of support: Nil

Conflict of interest: None

whereas second part was questions related to oral hygiene knowledge and oral hygiene practices of maternal mothers. Knowledge was measured by giving scores to their answers. Scoring was done on the basis of good, average, and poor scores. The exam was conducted by using 21 questions and hence

- Poor knowledge-score between 0 and 7

- Fair knowledge-score between 8 and 14

- Good knowledge-score $>14$

After the questionnaire was filled by the mothers, their children were screened for oral hygiene index. The scores were noted down. The Questionnaire was as follows:

- Name:

- Age:

- Education:

- Professional degree

- Graduate or post graduate

- Intermediate or post high school diploma

- High school certificate

- Primary school certificate

- Illiterate

(-) The Author(s). 2019 Open Access This article is distributed under the terms of the Creative Commons Attribution 4.0International License (https://creativecommons. org/licenses/by-nc/4.0/), which permits unrestricted use, distribution, and non-commercial reproduction in any medium, provided you give appropriate credit to the original author(s) and the source, provide a link to the Creative Commons license, and indicate if changes were made. The Creative Commons Public Domain Dedication waiver (http://creativecommons.org/publicdomain/zero/1.0/) applies to the data made available in this article, unless otherwise stated. 
- Occupation:

- Professional

- Semiprofessional

- Clerical, shop owner/farm

- Skilled worker

- Semi-skilled worker

- Unskilled worker

- Unemployed

- Monthly income:

- More than or equal to Rs 52,734

- Between Rs 26,355 to 52,733

- Between Rs 19,759 to 26,354

- Between Rs 13,161 to 19,758

- Between Rs 7,887 to 13,160

- Between Rs 2641 to 7886

- Less than Rs 2,640

- Dietary habits

(a) Does prolonged bottle feeding cause caries?

- No

- Yes

- Don't know

(b) Can excessive intake of food containing sugar cause caries?

- No

- Yes

- Don't know

(c) When is it best to give drinks and foods containing sugar?

- At meals

- In between meals

- When the child demands

(d) If the baby is let to sleep all night with milk in the mouth, is it harmful?

- No

- Yes

- Don't know

(e) Does spoon sharing between mother and child cause caries?

- No

- Yes

- Don't know

(f) Does feeding milk at bedtime cause early childhood caries?

- No

- Yes

- Don't know

- Brushing knowledge and practices

(a) How many times do you brush your teeth?

- 2 times

- 1 time

- After every meal

(b) Is rinsing important after every food intake?

- Yes

- No

- Don't know (c) When do you change your toothbrush?

- Every 3-6 months

- Every year

- When the bristles are frayed

(d) How much toothpaste should be used?

- Pea sized

- Full length

- Does not matter

(e) Do you know about the different brushing techniques?

- No

- Yes

- Don't know

- Brushing habits of the child

(a) How many times do you brush your child's teeth?

- Twice a day

- Once a day

- After every meal

(b) What type of toothbrush is best for the child?

- Small

- Large

- Does not matter

(c) Does the toothpaste for children differ from adults?

- No

- Yes

- Does not matter

(d) How should you brush your child's teeth?

- Standing behind the child

- Standing in front of the child

- Don't know

(e) How does your child brush his teeth?

- Happily

- Sad

- Resistant

(e) Are there different brushing techniques for children?

- No

- Yes

- Don't know

- Knowledge regarding dental awareness

(a) When should the child's 1st dental visit be?

- When the tooth erupts

- At 1 year

- When you see decay in the tooth

(b) Do the cavities in the tooth matter because the tooth will fall off anyway?

- No

- Yes

- Don't know 
(c) Is cleaning the child's mouth before tooth eruption important?

- No

- Yes

- Don't know

(d) Source of information on taking care of your child's oral hygiene?

- Dentist

- T.V

- Elders in the family

- Do you know the role of a Pedodontist

- No

- Yes

\section{Results}

The study group comprised of total 100 mothers and their respective 100 children.

\section{Distribution of mothers according to their oral hygiene knowledge score (Fig. 1)}

\begin{tabular}{lll}
\hline Knowledge score & Number of mothers & Percentage \\
\hline 0-7 (poor knowledge) & 11 & 11 \\
8-14 (average knowledge) & 73 & 73 \\
15-22 (good knowledge) & 16 & 16 \\
\hline
\end{tabular}

The data obtained were analyzed by using SPSS (Statistical Package for the Social Sciences SPSS Inc., IBM, INDIA) version 20.0 for windows. Mean and standard deviation (SD) were calculated for each clinical parameter. One-way analysis of variance (ANOVA) test was used for evaluation of the association between maternal mothers' oral hygiene knowledge, practices, and oral hygiene status of their children. Independent $t$ test was used to find the impact of mothers' oral hygiene practices on oral hygiene status of their children. Significance for all statistical tests was predetermined at a $p$ value $\leq 0.05$.

\section{Children's oral hygiene status in relation to mother's oral hygiene knowledge}

\begin{tabular}{lllll}
\hline $\begin{array}{l}\text { Mother's } \\
\text { knowledge }\end{array}$ & $\begin{array}{l}\text { Number of } \\
\text { mothers }\end{array}$ & $\begin{array}{l}\text { OHIS } \pm S D \\
\text { (children) }\end{array}$ & Fvalue & pvalue \\
\hline Good & 16 & $17.58 \pm 2.98$ & 53.27 & $<0.0001^{*}$ \\
Average & 73 & $9.84 \pm 4.02$ & & \\
Poor & 11 & $3.46 \pm 1.12$ & & \\
\hline
\end{tabular}

*Significant when $p$ value $<0.05$

The above table depicts the correlation between mother's oral hygiene knowledge and oral hygiene status of their children. One-way ANOVA was applied to determine the correlation between maternal mothers' oral hygiene knowledge and oral hygiene status of their children. It was found that maternal mothers' oral hygiene knowledge had a significant correlation with oral hygiene status of their children ( $p$ value $=<0.0001$ ). On further analysis by post hoc Tukey test, it was found that there was a statistically significant difference in mean OHI-S score (3.46) of children whose mothers had poor oral hygiene knowledge when compared to mean

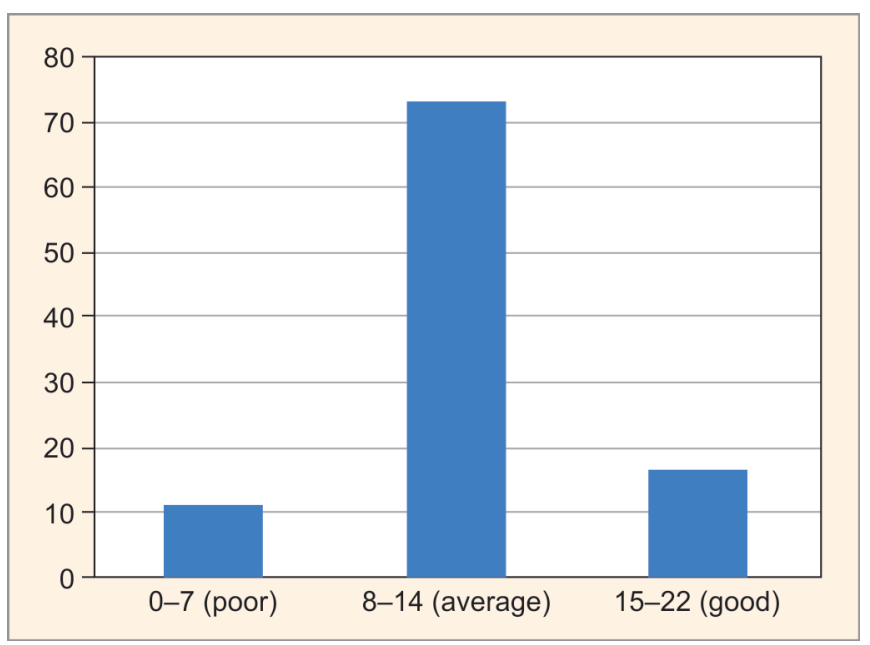

Fig. 1: Demographic information basis on good, average, poor candidates

OHI-S score (17.58) of children whose mothers had good hygiene knowledge.

\section{Discussion}

Oral health knowledge of mothers/guardians has an influence over the oral health of children as these habits are established during infancy and maintained throughout childhood. Mothers play an important function as role models for their children. ${ }^{5} \mathrm{~A}$ good understanding of parental knowledge, attitudes, beliefs, and awareness regarding oral health, habits, and hygiene is essential for the effective implementation of oral health promotion efforts aimed at improving the dental health of preschool children. ${ }^{8}$

A majority of mothers had knowledge regarding sugar intake, $63 \%$ knew that excessive sugar causes dental caries which was in according to studies by Shetty et al., Suresh et al., Kumar et al., and Linn et al. ${ }^{5,8-10}$ Only $49 \%$ of mothers had knew that prolonged bottle feeding will cause caries. In studies done by Shetty et al. and Kumar et al., the percentage of mothers was higher. ${ }^{8,9}$ In all, $26 \%$ mothers believed that spoon sharing between child and mother will cause dental caries, while $74 \%$ mothers had no knowledge regarding it. This was in contradiction to Shetty et al. and was in accordance with Chhabra and Chhabra. ${ }^{8,11}$

Majority of the mothers had poor knowledge regarding oral hygiene habits of self except for the quantity of toothpaste to be used. The results of study by Shetty et al. were much higher than the present study. ${ }^{8}$ When it came to brushing habits of the child, there was equal response for brushing once or twice a day. Only $38 \%$ of the mothers knew of availability of different toothpaste for children. While $52 \%$ of the children brushed their teeth sadly. In all, $62 \%$ of the mothers knew that a small sized toothbrush is used for children. The poor knowledge of mothers regarding their own brushing habits had an impact on the brushing habits of their children.

In all, $47 \%$ of mothers believed that cleaning the oral cavity before tooth eruption is essential, while $37 \%$ of the mothers had no knowledge over it. This was line with studies by Suresh et al. and Shetty et al. ${ }^{5,8}$

Elders in the family were the primary source of information for $48 \%$ of the mothers, while only $30 \%$ of them got information from the dentist. Studies by Shetty et al. and Chhabra and Chhabra also showed higher dependence of mothers on elders for 
information..$^{8,11}$ The children whose parents ignored the importance of primary teeth or paid less attention toward decay in these teeth were more susceptible to early childhood caries. ${ }^{8}$

There were limitations to the study, as the study was done on the outskirts of the city; hence, the literacy rate was mixed. Studies with children and parents of rural areas are advised as it will increase awareness, knowledge, and prevention of oral diseases and inculcate good hygiene practices among the rural areas. Habits developed during childhood form a basic foundation for better oral health practices and motivates for regular dental checkup.

\section{ConcLusion}

Based on the findings of this survey, mothers knowledge, practices, and awareness about oral health is important and has an impact on the child's oral health. Preventive strategies, importance of deciduous teeth, and education of oral hygiene practices should be given importance and programs should be conducted for parents.

\section{References}

1. Noar SM. A health educator's guide to theories of health behavior. Int Q Community Health Educ 2005-2006;24(1):75-92. DOI: 10.2190/ DALP-3F95-GCT3-M922.

2. Christensen $P$. The health-promoting family: a conceptual framework for future research. Soc Sci Med 2004;59(2):377-387. DOI: 10.1016/j. socscimed.2003.10.021.

3. Okada M, Kawamura M, Kaihara Y, et al. Influence of parents' oral health behaviour on oral health status of their school children: an exploratory study employing a causal modelling technique.
Int J Paediatr Dent 2002;12(2):101-108. DOI: 10.1046/j.1365263X.2002.00338.x.

4. Rajanna V, Khanagar S, Naganandini S. Oral hygiene knowledge and practices among mothers of 3- to 6-year-old preschool children visiting anganwadis of Bangaluru city. J Indian Assoc Public Health Dent 2019;17(1):76-79. DOI: 10.4103/jiaphd.jiaphd_117_18.

5. Suresh BS, Ravishankar TL, Chaitra TR, et al. Mother's knowledge about pre-school child's oral health. J Indian Soc Pedod Prev Dent 2010;28(4):282-287. DOI: 10.4103/0970-4388.76159.

6. Saied-Moallemi Z, Virtanen Jl, Ghofranipour F, et al. Influence of mothers' oral health knowledge and attitudes on their children's dental health. Eur Arch Paediatr Dent 2008;9(2):79-83. DOI: 10.1007/ BF03262614.

7. Mani SA, Aziz AA, John J, et al. Knowledge, attitude and practice of oral health promoting factors among caretakers of children attending day-care centers in Kubang Kerian, Malaysia: a preliminary study. J Indian Soc Pedod Prev Dent 2010;28(2):78-83. DOI: 10.4103/09704388.66741.

8. Shetty RM, Deoghare A, Rath S, et al. Influence of mother's oral health care knowledge on oral health status of their preschool child. Saudi J Oral Sci 2016;3(1):12-16. DOI: 10.4103/1658-6816.174291.

9. Kumar RP, John J, Saravanan S, et al. Oral health knowledge, attitude and practices of patients and their attendants visiting College of Dental Surgery, Saveetha University, Chennai. J Indian Assoc Public Health Dent 2009;7(13):43-53.

10. Lin HC, Wong MC, Wang ZJ, et al. Oral health knowledge, attitudes, and practices of Chinese adults. J Dent Res 2001;80(5):1466-1470. DOI: 10.1177/00220345010800051601.

11. Chhabra N, Chhabra A. Parental knowledge, attitudes and cultural beliefs regarding oral health and dental care of preschool children in an Indian population: a quantitative study. Eur Arch Paediatr Dent 2012;13(2):76-82. DOI: 10.1007/BF03262848. 